\title{
PRODUÇÃO DE COMPOSTOS $\alpha$-HIDROXIFOSFONATOS OPTICAMENTE ATIVOS UTILIZANDO CÉLULAS ÍNTEGRAS DE MICRORGANISMOS
}

\author{
L. M. SATO ${ }^{1}$, T. N. KITAMURA ${ }^{1}$, L. C. FARDELONE ${ }^{2}$, J. A. R. RODRIGUES ${ }^{2}$ \\ e P. J.S. MORAN ${ }^{2}$ \\ ${ }^{1}$ Universidade Estadual de Campinas, Faculdade de Engenharia Química \\ ${ }^{2}$ Universidade Estadual de Campinas, Instituto de Química \\ E-mail para contato: moran@iqm.unicamp.br
}

\begin{abstract}
RESUMO - As reduções enantiosseletivas dos cetofosfonatos 1a-c por Lactobacillus brevis CCT 3745 forneceram (S)-(-)-((4-clorofenil)(hidroxi)metil)

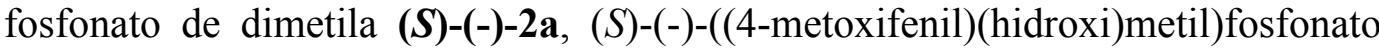

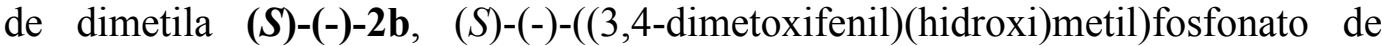
dimetila (S)-(-)-2c e com o uso de Candida albicans CCT 5847 forneceram $(R)-$ $(+)-((4-c l o r o f e n i l)(h i d r o x i) m e t i l)$ fosfonato de dimetila $(\boldsymbol{R})-(+)-\mathbf{2 a},(R)-(+)-((4-$ metoxifenil) (hidroxi)metil) fosfonato de dimetila $(\boldsymbol{R})-(+)-\mathbf{2 b}$ e $(R)-(+)-((3,4-$ dimetoxifenil) (hidroxi)metil)fosfonato de dimetila $(\boldsymbol{R})-(+)-2 \mathrm{c}$ com rendimentos entre 78-90\%. Os $(S)-(-)$ - e $(R)-(+)$ - $\alpha$-hidroxifosfonatos 2a-c são importantes intermediários para síntese de produtos de química fina, agroquímicos e fármacos.
\end{abstract}

\section{INTRODUÇÃO}

Os compostos $\alpha$-hidroxifosfonatos opticamente ativos (quirais) são compostos importantes dentro da classe de organofosforados devido as suas propriedades biológicas (DEMMER et al., 2011) e também por serem intermediários em química fina, farmacêutica e agrícola, principalmente como inibidores enzimáticos (GREMBECKA et al., 2003), antibióticos (DAKE et al., 2011), agentes antivirais (MOORE e DREYER, 1993), antitumorais (KRAICHEVA et al., 2009), pesticidas (KAFARSKI e LEJCZAK, 2004), entre outros.

Os compostos organofosforados possuem ligação direta fósforo-carbono (P-C), formando moléculas com centros quirais, cuja configuração espacial específica influencia diretamente na atividade da molécula, pois estes compostos organofosforados são análogos aos aminoácidos.

$\mathrm{Na}$ literatura estão descritas várias metodologias para a obtenção de compostos $\alpha$ hidroxifosfonatos, como o uso de catalisadores organometálicos (LIN et al., 2013), de indutores quirais (OLSZEWSKI, 2015; ALEGRE-REQUENA et al., 2014), uso de enzimas isoladas, mas necessitam de coenzimas, cofatores, que normalmente possuem custos elevados. O processo também necessita de um sistema para reciclagem destes cofatores, para mantê-lo eficiente e economicamente viável (KROUTIL et al., 2004). No entanto a redução enantiosseletiva de cetofosfonatos, bem como a resolução de $\alpha$-hidroxifosfonatos 
(MAJEWSKA et al., 2005) por células íntegras e enzimas tem recebido atenção nos últimos anos, pois estão dentre os métodos de química verde para a obtenção de compostos opticamente ativos (BRZEZIŃSKA-RODAK et al., 2011).

A biocatálise é um dos principais métodos utilizados em síntese enantiosseletiva devido ao uso de enzimas e células íntegras, e estas possuem alta químio-, regio- e estereosseletividade (CAZETTA et al., 2014; FARDELONE et al., 2011; RODRIGUES et al., 2004). Normalmente as condições de reações são brandas, pois utilizam baixas temperaturas ou ambiente e pressão atmosférica, e compostos "não naturais" podem ser aceitos como substratos. Assim, a biocatálise possui vantagens como estratégia de síntese, pois consome menos energia, normalmente não há subprodutos de reação, gera resíduos biodegradáveis e é economicamente viável devido ao menor custo em relação aos complexos metálicos (catalisadores).

Neste trabalho, a preparação de derivados organofosforados com bons rendimentos químicos (78-90\%) e a biotransformação destes organofosforados mediada por Lactobacillus brevis CCT 3745 e Candida albicans CCT 5847 fornecendo enantiosseletividade na obtenção de $\alpha$-hidroxifosfonatos opticamente ativos foram reportados.

\section{MATERIAIS E MÉTODO}

Os compostos 4-clorobenzaldeído, 4-metoxibenzaldeído, 3,4-dimetoxibenzaldeído e ácido oxálico foram adquiridos da Sigma-Aldrich Co. e os compostos racêmicos ( \pm )-((4clorofenil)(hidroxi)metil)fosfonato de dimetila ( \pm )-2a, $( \pm)-((4-m e t o x i f e n i l)(h i d r o x i) m e t i l)$ fosfonato de dimetila ( \pm )-2b e $( \pm)-((3,4$-dimetoxifenil)(hidroxi)metil)fosfonato de dimetila $( \pm)-2 c$ foram sintetizados de acordo com o método descrito por VAHDAT et al. (2008). Já os compostos (4-clorobenzoil)fosfonato de dimetila 1a, (4-metoxibenzoil)fosfonato de dimetila 1b e (3,4-dimetoxibenzoil)fosfonato de dimetila 1c foram sintetizados de acordo com metodologia descrita por MOORE e FINNEY (2002). Os demais solventes e reagentes são comerciais e possuem grau analítico.

\subsection{Condições de cultura dos microrganismos}

A bactéria Lactobacillus brevis CCT 3745 e a levedura Candida albicans CCT 5847 foram adquiridas da Fundação André Tosello, Campinas-SP, e foram cultivadas utilizando meio de cultura contendo $3 \% \mathrm{~m} / \mathrm{v}$ de extrato de levedura e $3 \% \mathrm{~m} / \mathrm{v}$ de peptona de soja, componentes estes utilizados em produção industrial, e com certificação de isenção de componentes animais, em $100 \mathrm{~mL}$ de água, suplementado com $0,2 \% \mathrm{~m} / \mathrm{v}$ de glicose. Os microrganismos foram mantidos por 16 horas de incubação à temperatura de $30^{\circ} \mathrm{C}$ em incubadora refrigerada, $0,54 \mathrm{~g}$, antes do uso. Todos os materiais utilizados foram esterilizados em autoclave à temperatura de $121{ }^{\circ} \mathrm{C}$, por 30 minutos, e os microrganismos foram manipulados em cabine de fluxo laminar. Após o crescimento do microrganismo este foi centrifugado, $1844 \mathrm{~g}$ por 30 minutos, resuspenso em $200 \mathrm{~mL}$ de água e centrifugado, $1844 \mathrm{~g}$ por 30 minutos, e resuspenso em $100 \mathrm{~mL}$ de água para o uso nos processos de biorredução. 


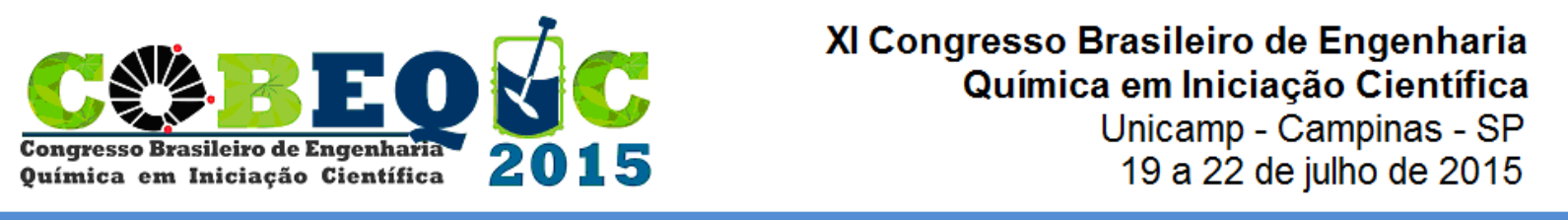

\subsection{Processo para a obtenção dos $\alpha$-hidroxifosfonatos racêmicos ( \pm -2a-c}

Os ( \pm )- $\alpha$-hidroxifosfonatos 2a-c foram sintetizados por adição equimolar do aldeído correspondente em trietilfosfito, seguido da adição de $0,10 \mathrm{~mol} \%$ de ácido oxálico, e na ausência de solvente. A mistura reacional foi mantida sob agitação magnética e à temperatura de $80{ }^{\circ} \mathrm{C}$ por 2 horas. O produto bruto foi extraído com acetato de etila e lavado com bicarbonato de sódio, e em seguida rotaevaporado e purificado através de sistema de cromatografia Isolera One da Biotage utilizando gradiente de solvente hexano/acetona.

\subsection{Processo para a obtenção dos cetofosfonatos 1a-c}

Os cetofosfonatos 1a-c foram sintetizados por adição de $6 \mathrm{mmol}$ de IBX em uma solução de $2 \mathrm{mmol}$ de $\alpha$-hidroxifosfonatos $\mathbf{2 a - c}$ correspondente em $30 \mathrm{~mL}$ de acetonitrila anidra. A mistura reacional foi mantida sob agitação magnética e à temperatura de $80^{\circ} \mathrm{C}$ por 1 hora. O produto bruto foi filtrado e transferido para um funil de separação para extração com acetato de etila, seco com sulfato de sódio anidro, rotaevaporado e purificado através de sistema de cromatografia Isolera One da Biotage utilizando gradiente de solvente hexano/acetona.

\subsection{Processo de biorredução dos cetofosfonatos 1a-c}

Os cetofosfonatos 1a-c $(0,61 \mathrm{mmol})$, dissolvidos em $0,5 \mathrm{~mL}$ de etanol foram adicionados a uma suspensão de $4 \mathrm{~g}$ de células íntegras em $100 \mathrm{~mL}$ de água. As suspensões microbianas foram mantidas sob agitação, $0,54 \mathrm{~g}$, e à temperatura de $30^{\circ} \mathrm{C}$ em incubadora refrigerada por 18 horas. Os produtos brutos foram extraídos com acetato de etila e purificados através de sistema de cromatografia Isolera One da Biotage utilizando gradiente de solvente hexano/acetona.

\section{RESULTADOS E DISCUSSÃO}

Os organofosforados 1a-c foram sintetizados segundo a metodologia de VAHDAT et al. (2008) a partir de 4-clorobenzaldeído, 4-metoxibenzaldeído e 3,4-dimetoxibenzaldeído reagindo com 1,1 equivalente de trimetilfosfito, na ausência de solvente e à temperatura de 60 ${ }^{\circ} \mathrm{C}$ fornecendo os $\alpha$-hidroxifosfonatos 1a-c racêmicos, os quais foram oxidados com ácido 2iodoxibenzóico (IBX) em acetonitrila anidra à temperatura de $80^{\circ} \mathrm{C}$ (MOORE e FINNEY, 2002).

A obtenção dos hidroxifosfonatos $(S)-(-)$-2a-c e $(R)-(+)-\mathbf{2 a - c}$ foi realizada através da reação de biorredução dos cetofosfonatos 1a-c mediada por células íntegras de Lactobacillus brevis CCT 3745 e Candida albicans CCT 5847 respectivamente, e estão representados, de forma esquemática na Figura 1. 
Figura 1 - Biorredução de cetofosfonatos 1a-c por Lactobacillus brevis CCT 3745 e Candida albicans CCT 5847.

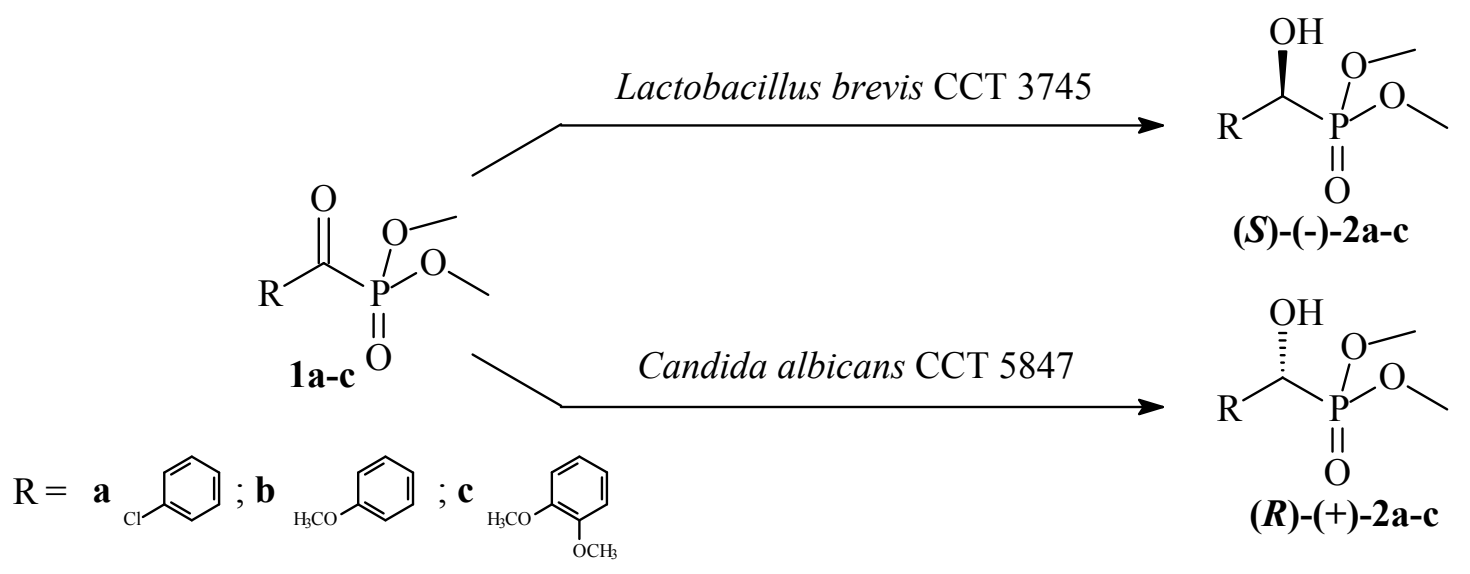

$\mathrm{Na}$ Tabela 1, estão reportados os rendimentos químicos, isolados, e a configuração absoluta dos $\alpha$-hidroxifosfonatos 2a-c obtidos através da biorredução dos cetofosfonatos 1a-c por Lactobacillus brevis CCT 3745 e Candida albicans CCT 5847.

Tabela 1 - Biorredução de cetofosfonatos 1a-c por Lactobacillus brevis CCT 3745 e Candida albicans CCT 5847.

\begin{tabular}{ccccc}
\hline Substrato & Produto & Microrganismo & Rendimento isolado $(\%)$ & {$[\boldsymbol{\alpha}]_{\mathbf{D}}{ }^{\mathbf{2 5}}$} \\
\hline 1a & $(\boldsymbol{S})-2 a$ & Lactobacillus brevis CCT 3745 & 80 & -52 \\
$\mathbf{1 b}$ & $(\boldsymbol{S})-\mathbf{2 b}$ & Lactobacillus brevis CCT 3745 & 81 & -43 \\
$\mathbf{1 c}$ & $(\boldsymbol{S})-2 \mathbf{c}$ & Lactobacillus brevis CCT 3745 & 78 & -13 \\
$\mathbf{1 a}$ & $(\boldsymbol{R})-\mathbf{2 a}$ & Candida albicans CCT 5847 & 82 & +37 \\
$\mathbf{1 b}$ & $(\boldsymbol{R})-2 \mathbf{b}$ & Candida albicans CCT 5847 & 90 & +41 \\
$\mathbf{1 c}$ & $(\boldsymbol{R})-\mathbf{2 c}$ & Candida albicans CCT 5847 & 84 & +15 \\
\hline
\end{tabular}

Nota: rotação óptica específica $\left([\alpha]_{\mathrm{D}}\right)$ refere-se ao ângulo do desvio do plano da luz polarizada (BARRON, 2009)

Os rendimentos químicos obtidos foram superiores a $78 \%$ para todos os substratos submetidos à biorredução, o que demonstrou que o processo é uma boa metodologia de síntese para a produção de $\alpha$-hidroxifosfonatos opticamente ativos. As configurações absolutas foram determinadas através da comparação das medidas de rotação óptica $\left([\alpha]_{\mathrm{D}}{ }^{25}\right)$ com as descritas na literatura (LIN et al., 2013).

O mecanismo das reações de biorreduções foi efetuado através da transferência de hidreto pela coenzima NADH ou NADPH mediada pela enzima desidrogenase (ALEIXO et al., 1993). É interessante notar que as biorreduções dos substratos 1a-c são realizadas com bons a excelentes rendimentos dos produtos isolados $\mathbf{2 a - c}$ mesmo tendo grupos substituintes doadores de elétron por ressonância como 4-Cl-, 4- $\mathrm{CH}_{3} \mathrm{O}-$ e 3,4-diCH $\mathrm{H}_{3} \mathrm{O}$ - ligados ao anel aromático. A diminuição da reatividade causada por esses grupos substituintes deve ser contrabalanceada pelo grupo fosfonato ligado diretamente à ligação $\mathrm{C}=\mathrm{O}$. 
Uma das vantagens de se utilizar os microrganismos Lactobacillus brevis CCT 3745 e Candida albicans CCT 5847 é a enantiocomplementariedade na obtenção dos $\alpha$ hidroxifosfonatos 2a-c, podendo ser utilizados de acordo com a necessidade de obtenção da configuração desejada, o que demonstra que a metodologia aplicada nas biotransformações é de fundamental importância para serem aplicadas em síntese de compostos opticamente ativos.

É importante ressaltar que estes compostos $\alpha$-hidroxifosfonatos opticamente ativos podem ser utilizados em rotas sintéticas para a produção de intermediários para as indústrias de química fina, agroquímica e farmacêutica.

\section{CONCLUSÕES}

Os resultados obtidos das reduções enantiosseletivas com os microrganismos Lactobacillus brevis CCT 3745 e Candida albicans CCT 5847 forneceram bons rendimentos isolados (78-90\%) e os álcoois $(S)-(-)$ - e $(R)-(+)$ - $\alpha$-hidroxifosfonatos 2a-c podem ser utilizados como intermediários de síntese para produtos de química fina, agroquímicos e fármacos.

\section{AGRADECIMENTOS} CNPq.

Os autores agradecem o suporte financeiro à FAPESP (2014/00108-9), a CAPES e ao

\section{REFERENCIAS}

ALEIXO L. M.; CARVALHO, M.; MORAN, P. J. S. AND RODRIGUES, J. A. R.. Hidride transfer versus electron transfer in the Baker's yeast reduction of $\alpha$ haloacetophenones. Bioorganic \& Medicinal Chemistry Letters, v. 3, p. 1637-1642, 1993.

ALEGRE-REQUENA, J. V., MARQUÉS-LÓPEZ, E., MIGUEL, P. J. S., HERRERA, R. P.. Organocatalytic enantioselective hydrophosphonylation of aldehydes. Org. Biomol. Chem., v. 12, p. 1258-1264, 2014.

BARRON, L. D.. Molecular light scattering and optical activity. Cambridge University Press, $2^{\mathrm{a}}$ edição, 2009.

BRZEZIŃSKA-RODAK， M.， KLIMEK-OCHAB， M.; ŻYMAŃCZYK-DUDA， E.; KAFARSKI, P.. Biocatalytic resolution of enantiomeric mixtures of 1aminoethanephosphonic acid. Molecules, v. 16, p. 5896-5904, 2011.

CAZETTA, T.; MORAN, P. J. S.; RODRIGUES, J. A. R.. Highly enantioselective deracemization of 1-phenyl-1,2-ethanediol and its derivatives by stereoinversion using Candida albicans in a one-pot process. J. Mol. Cat. B: Enzymatic, v. 109, p. 178-183, 2014.

DAKE，S. A.; RAUT，D. S.; KHARAT，K.R.; MHASKE，R. S.; DESHMUKH， S. U.; PAWAR, R. P.. Ionic liquid promoted synthesis, antibacterial and in vitro antiproliferative activity of novel $\alpha$-aminophosphonate derivatives. Bioorg. Med. Chem. Lett., v. 21, p. 2527-2532, 2011. 
DEMMER, C. S.; KROGSGAARD-LARSEN, N.; BUNCH, L.. Review on Modern Advances of Chemical Methods for the Introduction of a Phosphonic Acid Group. Chem. Rev., v. 111, p. 7981-8006, 2011.

FARDELONE, L. C.; RODRIGUES, J. A. R.; MORAN, P. J. S.. Chiral Pharmaceutical Intermediaries Obtained by Reduction of 2-Halo-1-(4-substituted phenyl)-ethanones Mediated by Geotrichum candidum CCT 1205 and Rhodotorula glutinis CCT 2182. Enzyme Res., 2011:976368, 2011.

GREMBECKA, J.; MUCHA, A.; CIERPICKI, T.; KAFARSKI, P.. The most potente organophosphorus inhibitors of leucine aminopeptidase. Structure-based design, chemistry, and activity. J. Med. Chem., v. 46, p. 2641-2655, 2003.

KAFARSKI, P.; LEJCZAK., B.. Application of bacteria and fungi as biocatalysts for the preparation of optically active hydroxyphosphonates. J. Mol.Catal. B: Enzym., v. 29, p. 99-104, 2004.

KRAICHEVA, I.; BOGOMILOVA, A.; TSACHEVA, I.; MOMEKOV, G.; TROEV, K.. Synthesis, NMR charakterysation and in vitro antitumor evaluation of new aminophosphonic acid diesters. Eur. J. Med. Chem., p. 44, p. 3363-3367, 2009.

KROUTIL, W.; MANG, H.; KLAUS, E. FABER, K. KROUTIL, W.; MANG, H.; KLAUS, E. FABER, K.. Recent advances in the biocatalytic reduction and oxidation of secalcohol. Cur. Op. Chem. Biol., v. 8, p. 120-126, 2004.

LIN SUN, L.; GUO, Q.-P.; LI, X.; ZHANG, L.; LI, Y.-Y.; DA, C.-S.. C2-Symmetric homobimetallic zinc complexes as chiral catalysts for the highly enantioselective hydrophosphonylation of aldehydes. Asian J. Org. Chem., v. 2, p. 1031-1035, 2013.

MAJEWSKA, P.; KAFARSKI, P.; LEJCZAK, B.. Lipase-catalysed resolution of 1-hydroxyethane-P- phenylphosphinates. Pol. J. Chem., v. 79, p. 561-566, 2005.

MOORE, J. D.; FINNEY, N. S.. A Simple and advantageous protocol for the oxidation of alcohols with $o$-iodoxybenzoic acid (IBX). Org. Lett., v. 4, p. 3001-3004, 2002.

MOORE, M. L; DREYER, G. B.. Substrate-based inhibitors of HIV-1 protease. Perspect. Drug Discovery Des., v. 1, p. 85-108, 1993.

OLSZEWSKI, T. K.. Asymmetric synthesis of a-hydroxymethylphosphonates and phosphonic acids via hydrophosphonylation of aldehydes with chiral H-phosphonate. Tetrahedron: Asymmetry, v. 26, p 393-399, 2015.

RODRIGUES, J. A. R.; MORAN, P. J. S.; CONCEIÇÃO, G. J. A.; FARDELONE, L. C.. Recent advances in the biocatalytic asymmetric reductions of acetophenones and $\alpha, \beta$-unsuturated carbonyl compounds. Food. Technol. Biotechnol., v. 42, p. 295-303, 2004.

VAHDAT, S. M.; BAHARFAR, R.; TAJBAKHSH, M.; HEYDARI, A.; BAGBANIAN, S. M.; KHAKSAR, S.. Organocatalytic synthesis of $\alpha$-hydroxy and $\alpha$-aminophosphonates. Tetrahedron Lett., v. 49, p. 6501-6504, 2008. 